\title{
P-WAVE IMAGE OF THE CRUST AND UPPERMOST MANTLE IN SOUTHERN CALIFORNIA
}

\author{
Dapeng Zhao and Hiroo Kanamori
}

Seismological Laboratory, California Institute of Technology

\begin{abstract}
We have determined a P-wave tomographic image of the crust and uppermost mantle in southern California by using 131,372 P-wave arrival times from 6,437 local earthquakes recorded by the Caltech-USGS Southern California Seismic Network in the past twelve years. The obtained image has a spatial resolution of $25 \mathrm{~km}$ in the horizontal direction and $8-11 \mathrm{~km}$ in depth. The tomographic image is found to correlate well with major surface geological features. In the shallow crust, sedimentary basins such as the Los Angeles Basin, Ventura Basin and Santa Maria Basin are well imaged as low velocities, while batholiths such as the Peninsular Ranges and San Gabriel Mountains are imaged as high velocities. In the deeper crust, the velocity is low beneath the Mojave Desert, Coso volcanic area and Salton Trough, while it is high beneath the Great Valley, Continental Borderland and the major basins. A high-velocity layer exists in the mid-crust beneath the Salton Trough, in good agreement with a previous study using seismic explosions and gravity data. In the uppermost mantle, the velocity is low beneath southeastern Sierra Nevada and the volcanic areas while it is high beneath the Mojave Desert and along the Pacific coast.
\end{abstract}

\section{Introduction}

Many researchers have investigated seismic velocity structure of southern California (Figure 1) by inverting local earthquake arrival times [Ergas and Jackson, 1981; Hearn and Clayton, 1986a,b; Sung and Jackson, 1992] and teleseismic residuals [Raikes, 1980; Humphreys et al., 1984; Humphreys and Clayton, 1990; Baisi and Humphreys, 1992]. They found significant heterogeneities in the crust and upper mantle. The previous studies, however, did not determine a detailed structure within the crust because the block sizes in their tomographic inversions are larger than $30 \mathrm{~km}$. This prevents us from discussing in detail the tectonics of southern California, e.g., the depth extent of the major sedimentary basins, batholiths and large fault zones in the crust.

Recently Magistrale et al.[1992] constructed a 3-D crustal model by dividing southern California into 23 large provinces defined by the surface geology and deriving a 1D model for each province. For each province, the structure determined by earlier studies was used as the initial model for the inversion; the velocity structure within each province was assumed to be laterally homogeneous.

In the present study, we have used a modern method

Copyright 1992 by the American Geophysical Union.

Paper number 92GL02719

0094-8534/92/92GL-02719\$03.00 to determine a detailed P-wave tomographic image of the crust and uppermost mantle in southern California by taking advantage of the high density of seismic stations, and the high quality and great quantity of arrival times of the Caltech-USGS Southern California Seismic Network (Figure $2 \mathrm{a}$ ). The present result casts a new light on the complex structure and tectonics of southern California.

\section{Data and Inversion Procedure}

We have used arrival times recorded by the CaltechUSGS Southern California Seismic Network in the period from January 1981 to May 1992. Figure 2(a) shows the geographic locations of the 293 seismic stations we used. The stations are densely and uniformly distributed in the study area except for the Great Valley region.

More than 100,000 earthquakes have been recorded by the network during the past twelve years. In order to select the best set of events for the inversion, we divide the study area into blocks with spatial sizes of $8 \times 8 \times 2 \mathrm{~km}^{3}$. Among the earthquakes within each block, we selected the event which has the greatest number of P-arrivals and the smallest error for the hypocentral location. As a result, we selected 6,437 earthquakes; their epicentral locations are shown in Figure 2(b). All the events have at least $10 \mathrm{P}$ arrivals, many of them have more than $100 \mathrm{P}$-arrivals. The standard error for the hypocentral locations is less than 2 $\mathrm{km}$ for most of the events.

The total number of P-arrivals from the 6,437 earthquakes is 146,422. In order to avoid the effect of Pn velocity anistropy and the Moho depth variation, we used only the arrival times with epicentral distances shorter than 200 $\mathrm{km}$. Thus the number of data we actually used in the inversion is reduced to 131,372 . The accuracy of arrival time

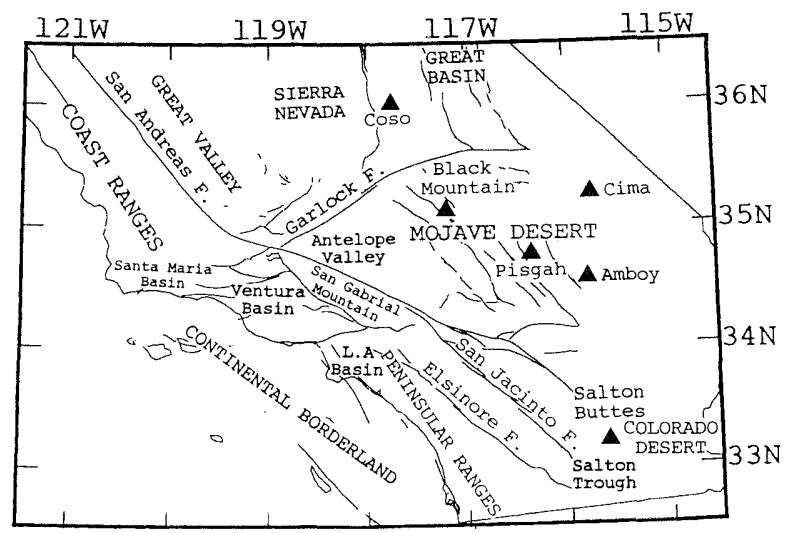

Fig. 1. Southern California. The locations of major faults (solid lines), volcanic areas (solid triangles) and other geographical areas referred to in the text are shown. 


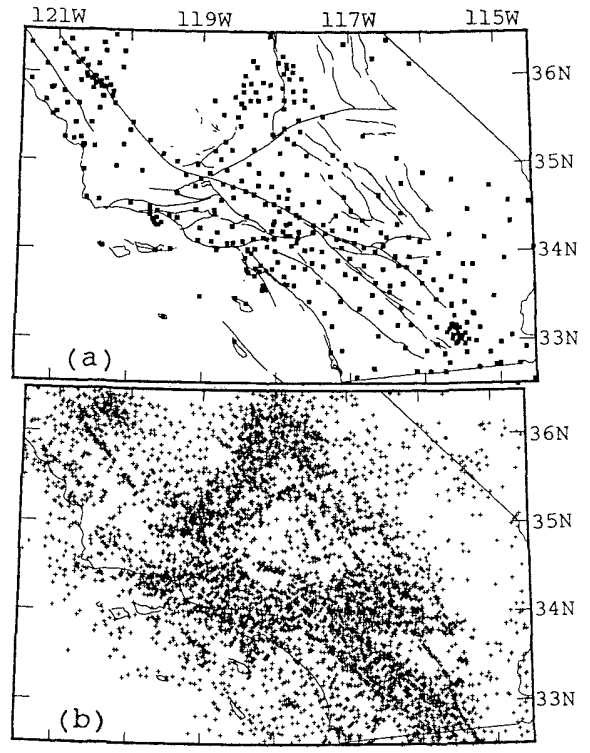

Fig. 2. (a) The Caltech-USGS Southern California Seismic Network. The locations of the 293 stations (solid squares) as of 1992 are shown. (b) Event Locations. The epicentral locations of 6,437 earthquakes used in this study are shown. These earthquakes generate 131,372 usable Pwave arrival times.

pickings is estimated to be about $0.1 \mathrm{sec}$ for most of the data.

To analyze the selected arrival times, we have used the tomography method of Zhao et al.[1992]. Although the conceptual approach of this method parallels that of Aki and Lee[1976], it has the following favorable features. (a) It is adaptable to a velocity structure with complicatedshaped discontinuities and with $3-\mathrm{D}$ velocity variations in the modelling space. We set 3-D grid nodes in the modelling space and take velocities at the nodes as unknown parameters. (b) Travel times and ray paths are calculated by using an efficient 3-D ray tracing technique [Zhao et al.,1992]. (c) LSQR algorithm of Paige and Saunders [1982] is used to conduct the inversion, allowing a great number of data to be used to solve a large tomographic problem. (d) The nonlinear tomographic problem is solved by iteratively conducting linear inversions. In each iteration source parameters and velocity structure are determined simultaneously. For details of the method, see Zhao[1991] and Zhao et al.[1992].

\section{Result}

We took the 1-D model of Kanamori and Hadley[1975] as the starting velocity model for the inversion. Applying the technique of Zhao et al.[1992] to the data set, we iteratively conducted a number of inversions by changing the spacing between grid nodes which are set up in the study area, and found a four-mesh layer grid-net with a grid spacing of $25 \mathrm{~km}$ in the horizontal direction is adequate for the present data set and gives a reasonable result. The four mesh layers are set up at $2,10,22$, and $33 \mathrm{~km}$, respectively. Figure 4 shows the configuration of the grid net in the horizontal direction. We simultaneously determined $6437 \times 4$ source parameters and 1577 velocity perturbations for the grid nodes with hit counts (number of rays passing through each node) larger than 20. More than $99 \%$ of the nodes have hit counts greater than 100 . The events used were relocated in the inversion process. A variance reduction amounting to $42 \%$ is achieved after the inversion. Figure 3 shows fractional $\mathrm{P}$-wave velocity perturbations (in \%) from the Kanamori and Hadley[1975] model on horizontal planes determined by the inversion. The main features of

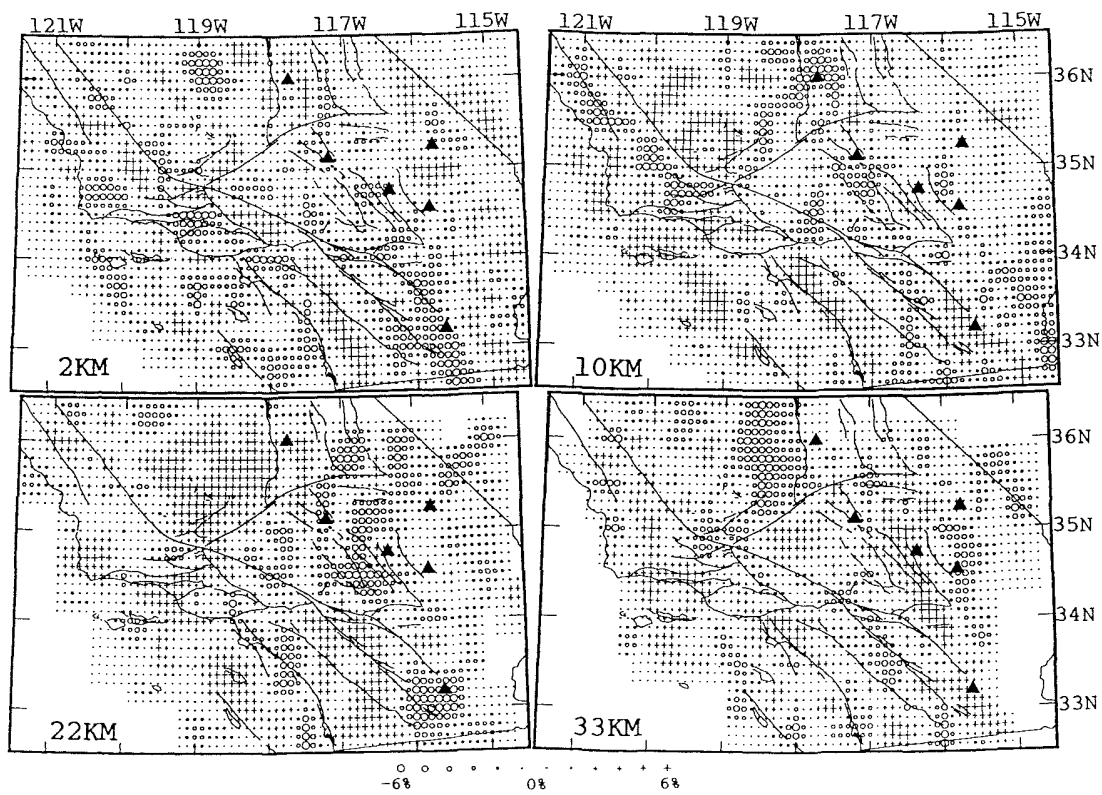

Fig. 3. Fractional P-wave velocity perturbations (in \%) at each grid mesh layer. Results are interpolated from grid distribution shown in Figure 4. The depth of each layer is shown at the lower-left corner of the map. Cross and circle symbols denote high and low velocities, respectively. The perturbation scale is shown below the figure. 
the obtained P-wave image are summarized as follows.

1. At the shallow depth $(2 \mathrm{~km})$, the $P$-wave image correlates well with the major surface geological features. The Los Angeles Basin, Ventura Basin, Santa Maria Basin and Salton Trough are imaged as low velocities, while the batholiths of the Peninsular Ranges, San Gabriel Mountains and southern Sierra Nevada are imaged as high velocities. All of the six volcanic areas in southern California are underlain by low velocity anomalies.

2. In the middle crust $(10 \mathrm{~km}$ depth), the velocity anomalies for the sedimentary basins and batholiths seen at a depth of $2 \mathrm{~km}$ disappear or become less prominent. The Peninsular Ranges batholith, however, still shows high velocity. In addition, high velocities exist in the Salton Trough and Great Valley region, while low velocities exist in the eastern Mojave Desert, Colorado Desert, Coso Volcanic area and Coastal Ranges. Note the abrupt velocity change across the northern part of the San Andreas Fault.

3. In the lower crust (22 km depth), the velocity is low in the Mojave Desert, Salton Trough and Great Basin, while it is high north of the Garlock Fault, and in a region including the southern Peninsular Ranges and the Elsinore and the San Jacinto fault zones. The velocity is also high beneath the Continental Borderland. The velocity changes abruptly across the Garlock Fault and the southern part of the San Andreas Fault.

4. In the uppermost mantle (33 km depth), we see a different picture from that of the crust. High velocities exist in the Antelope Valley and Mojave Desert and in the Pacific coastal regions, while low velocities exist in Sierra Nevada and around the Coso, Cima, Amboy, Black Mountain volcanic areas. Across the Garlock Fault, the velocity changes significantly.

\section{Resolution}

We used the checkerboard resolution test [Humphreys and Clayton, 1988; Inoue et al.,1990] to assess the adequacy of the ray coverage and to evaluate the resolution. To make a checkerboard, we assigned positive and negative velocity perturbations of $3 \%$ to the 3 -D grid nodes, the image of which is straightforward and easy to remember. Therefore just seeing the image of the synthetic inversion of the checkerboard, one can easily understand where the resolution is good and where it is poor. In the test we added random errors in a normal distribution with a standard deviation of $0.1 \mathrm{~s}$ to the arrival times calculated for the synthetic model. Figure 4 shows the result of the test. The resolution is high and the checkerboard pattern is correctly reconstructed for most part of the study area at 2 , 10 , and $33 \mathrm{~km}$ depths. The resolution is poor around the Great Valley region at 2 and $10 \mathrm{~km}$ depths due to the lack of station there. The resolution is relatively low at $22 \mathrm{~km}$ depth, because few earthquake occur around and below that depth, and the grid nodes are sampled mainly by the vertically propagating parts of refracted waves. At the edge of the study area the resolution is very low, which is expected.

\section{Discussion}

The Kanamori and Hadley[1975] model which we took as the starting velocity model is reliably constructed by

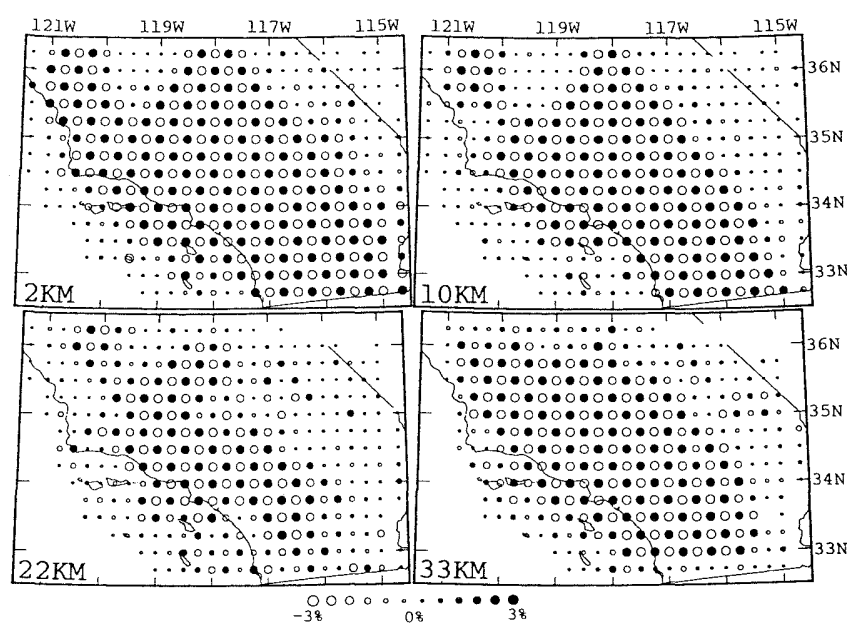

Fig. 4. Result of the checkerboard resolution test (see text) for each mesh layer. The grid separation in this test is one-fourth degree (about $25 \mathrm{~km}$ ). Solid and open circles denote high and low velocities, respectively. The scale is shown at the bottom of the figure.

using high accuracy arrival times from seismic explosions. This model consists of four constant-velocity layers without gradient. The details of the lower crust in this model are somewhat uncertain [Kanamori and Hadley, 1975]. In order to know how much the starting model affects the final tomographic image, we conducted several inversions by changing the velocity gradient and velocity values of the starting model. Although there are some changes in the amplitudes of the velocity anomalies, the pattern of the $\mathrm{P}$-wave images determined by these inversions is generally the same. Therefore we believe that the starting model has only a small effect on the tomographic image.

Previous studies found a Pn velocity anistropy in southern California by using $P_{n}$ waves with epicentral distances as long as $600 \mathrm{~km}$ [Vetter and Minster,1981; Hearn,1984; Sung and Jackson,1982]. In this study, we did not take into account the Pn velocity anistropy, which may have some effect on the obtained P-wave image. However, the effect is believed to be very small because all the Pn arrivals we used have epicentral distances shorter than 200 $\mathrm{km}$. These Pn waves propagate within the uppermost mantle not greater than $50 \mathrm{~km}$. In addition, rays traverse structure in many directions, tending to cancel out any anistropic contribution.

We did not include the Moho depth variation in this study. Referring to the studies of Zhao and Hasegawa [1991] and Zhao[1992] on the effect of the Moho depth variation, we consider that the pattern of the P-wave image may change little but the amplitude of velocity anomalies may have some variations when the Moho topography is taken into account. In addition, we did not use the very long rays of $P n$ waves, which may also help to alleviate the effect. Even so, we consider the P-wave image we obtained is influenced, in some degree, by the Moho depth variation. In the future study we will simultaneously determine the Moho topography and tomographic images by using both local earthquake and teleseismic data. Thus we may obtain a clearer picture of the deep structure in southern California. 
Although many features described above have been found by previous studies, we believe that a much more accurate and detailed $\mathrm{P}$-wave tomographic image of southern California has been obtained by this study. Due to the limited space, here we only discuss the Salton Trough region. Previous studies found a high crustal velocity for this area [Ergas and Jackson, 1981; Hearn and Clayton, 1986a,b; Sung and Jackson, 1992]. Magistrale et al.[1992] did not determine the structure deeper than $8 \mathrm{~km}$ in the Salton Trough and found the velocity is low in the shallow depth. In this study, we found low velocities in the shallow $(2 \mathrm{~km})$ and deep $(22 \mathrm{~km})$ crust and a high velocity in the middle crust $(10 \mathrm{~km})$ in the Salton Trough. Fuis et al.[1982] determined a detailed crustal structure in this area by using data from seismic explosions and gravity surveys. They found beneath the Salton Trough a high-density layer of mafic intrusive rocks at the mid-crust, while the materials at shallow and deep crust are of low-density and lowvelocity, which is consistent with the present result.

Acknowledgements. We appreciate the helpful discussions with K.Aki, D.L.Anderson, R.W.Clayton, T.Heaton, L.T.Silver and W.Huang. E.Humphreys, D.Wald and an anonymous referee critically read the manuscript and provided helpful comments, which improved the manuscript. The first author (DZ) was supported by the Southern California Earthquake Center (SCEC) and this is SCEC Publication No.10. This work was partially supported by a National Science Foundation grant, EAR-92-04748. Contribution No.5206, Division of Geological and Planetary Sciences, California Institute of Technology, Pasadena, CA 91125.

\section{References}

Aki,K. and W.H.K.Lee, Determination of three-dimensional velocity anomalies under a seismic array using first $\mathrm{P}$ arrival times from local earthquakes, 1 , A homogeneous initial model, J. Geophys. Res., 81, 4381-4399, 1976.

Biasi,G.P. and E.Humphreys, P-wave image of the upper mantle structure of central California and southern Nevada, em Geophys. Res. Lett., 19, 1161-1164, 1992.

Ergas,R.A. and D.D.Jackson, Spatial variations of seismic velocities in southern California, Bull. Seism. Soc. Am., 71, 671-689, 1981.

Fuis,G.S., W.D.Mooney, J.H.Healy, J.A.McMechan, and W.J.Lutter, Crustal structure of the Imperial Valley Region, U.S. Geol. Surv. Profess. Pap., 1254, 25-49, 1982.

Hearn,T.M., Pn travel times in southern California, $J$. Geophys. Res., 89, 1843-1855, 1984.

Hearn,T.M. and R.W.Clayton, Lateral velocity variations in southern California I. Results for the upper crust from Pg waves, Bull. Seism. Soc. Am., 76, 495-509, 1986a.
Hearn,T.M. and R.W.Clayton, Lateral velocity variations in southern California II. Results for the lower crust from Pn waves, Bull. Seism. Soc. Am., 76, 511-520, $1986 \mathrm{~b}$.

Humphreys,E. and R.W.Clayton, Adaptation of back prejection tomography to seismic travel time problems, $J$. Geophys. Res., 93, 1073-1085, 1988.

Humphreys,E. and R.W.Clayton, Tomographic image of southern California mantle, J. Geophys. Res., 95, 19725-19746, 1990.

Humphreys,E., R.W.Clayton, and B.H.Hager, A tomographic image of mantle structure beneath southern California, Geophys. Res. Lett., 11, 625-627, 1990.

Inoue,H., Y.Fuka.o, K.Tanabe, and Y.Ogata, Whole mantle P-wave travel time tomography, Phys. Earth and Planet. Inter., 59, 294-328, 1990.

Kanamori,H. and D.Hadley, Crustal structure and temporal velocity change in Southern California, Pure and Appl. Geophys., 113, 257-280, 1975.

Magistrale,H., H.Kanamori, and C.Jones, Forward and inverse three-dimensional $\mathrm{P}$ wave velocity models of the southern California crust, J. Geophys. Res., 97, 1411514135, 1992.

Paige,C.C. and M.A.Saunders, LSQR: An algorithm for sparse linear equations and sparse least squares, $A C M$ Trans. Math. Software, 8, 43-71, 1982.

Raikes, S.A., Regional variations in upper mantle structure beneath southern California, Geophys. J. R. Astron. Soc., 63, 187-216, 1980.

Sung, L.Y. and D.D.Jackson, Crustal and uppermost mantle structure under southern California, Bull. Seism. Soc. Am., 82, 934-961, 1992.

Vette, V. and J.B.Minster, Pn velocity anistropy in Southern California, Bull. Seism. Soc. Am., 71, 1511-1530, 1981.

Zhao,D., A tomographic study of seismic velocity structure in the Japan Islands, Ph.D. Thesis, Tohoku Univ., Sendai, Japan, 301pp, 1991.

Zhao,D., On the importance of an inhomogeneous starting model in seismic tomography, Seism. Res. Lett., 63, 56, 1992.

Zhao,D. and A.Hasegawa, P-wave tomographic imaging of the crust and upper mantle beneath the Japan Islands, in press, J. Geophys. Res., 1992.

Zhao,D., A.Hasegawa, and S.Horiuchi, Tomographic imaging of $\mathrm{P}$ and $\mathrm{S}$ wave velocity structure beneath northeastern Japan, in press, J. Geophys. Res., 1992.

H. Kanamori and D. Zhao, Seismological Laboratory 252-21, California Institute of Technology, Pasadena, CA 91125.

(Received September 10, 1992; accepted October 20, 1992.) 